\title{
BALANCED SCORECARD COMO APOIO À GESTÃO ESTRATÉGICA DE UMA UNIDADE DE INSTITUTO FEDERAL DE EDUCAÇÃO TECNOLÓGICA ${ }^{1}$
}

\author{
Marina Gomes Murta Moreno \\ Cassio Henrique Garcia Costa \\ Geraldo Tessarini Junior
}

\begin{abstract}
RESUMO
Esta pesquisa tem o objetivo de propor um modelo de Gestão Estratégica (GE) para uma unidade (campus) de um Instituto Federal de Educação, Ciência e Tecnologia (IF), formalizando-o por meio da adaptação do Balanced Scorecard (BSC). O estudo de caso baseou-se na coleta de dados pela aplicação da técnica de grupos focais, sendo as informações obtidas interpretadas qualitativamente pela atuação de um grupo de trabalho (GT) multidisciplinar. Através da construção e da proposição participativa e descentralizada de um BSC alternativo em uma organização pública, contribui-se para a redução de lacunas relacionadas à: i) resistência e ausência de inserção da comunidade acadêmica no processo de GE; e ii) utilização do BSC em IFs. Evidenciaram-se: i) a participação mais ativa de diversos membros organizacionais no processo de diagnóstico organizacional e de estruturação do modelo, buscando-se a sua efetiva legitimação; ii) a definição de estratégias organizacionais para a sistematização do Planejamento Estratégico (PE); e iii) a estruturação de um modelo de GE adequado às singularidades da instituição, consolidado pelo BSC. A nova arquitetura do BSC pode ser replicada a outras instituições de ensino similares, de modo a proporcionar estudos comparativos para verificação de sua validade externa. Esta pesquisa também reduz omissões da literatura sobre GE em IFs, detalhando o processo de elaboração de práticas estratégicas para a melhoria do desempenho organizacional.
\end{abstract}

Palavras-chave: Gestão Estratégica. Planejamento Estratégico. Balanced Scorecard. Instituto Federal de Educação, Ciência e Tecnologia.

\section{INTRODUÇÃO}

O Balanced Scorecard (BSC) figura-se entre uma das mais conhecidas e difundidas ferramentas de Gestão Estratégica (GE). Traduz a estratégia de negócios em objetivos estratégicos específicos, desdobrados em quatro perspectivas clássicas: financeira, clientes, processos internos, aprendizado e crescimento (KAPLAN; NORTON, 1997). Sua importância como apoio ao processo de tomada de decisão é relevante, já que converte o Planejamento

\footnotetext{
${ }^{1}$ MORENO, Marina Gomes Murta; COSTA, Cassio Henrique Garcia; TESSARINI JUNIOR, Geraldo. Balanced scorecard como apoio à gestão estratégica de uma unidade de Instituto Federal de Educação Tecnológica.

ForScience: revista científica do IFMG, Formiga, v. 7, n. 2, e00608, jul./dez. 2019. DOI:

10.29069/forscience.2019v7n2.e608.
}

2 Autor para correspondência: Marina Gomes Murta Moreno, marina.murta@ifsuldeminas.edu.br 
Estratégico (PE) em ações, alinhando as atividades organizacionais à sua estratégia, por meio da medição de indicadores de desempenho e do gerenciamento de informações.

Embora a utilização do BSC se dê com maior ênfase na iniciativa privada (HOQUE, 2014), essa ferramenta pode (e deve) ser adaptada para organizações públicas (KAPLAN; NORTON, 1997; BOCCI, 2005). Apesar de não atuarem sob a mesma lógica de competição presente no setor privado, essas organizações apresentam a análoga necessidade de consolidação de objetivos, valores e conhecimentos em ações e estratégias que permitam um desempenho mais adequado (RODRIGUES, 2015).

Pertencentes à Administração Pública Federal, os Institutos Federais (IFs) são autarquias vinculadas ao Ministério da Educação (MEC), criadas pela Instituição da Rede Federal de Educação Profissional, Científica e Tecnológica (BRASIL, 2008). Desempenham importante papel para o desenvolvimento econômico e social, realizando atividades científicas e tecnológicas. Diferem-se das Instituições de Ensino Superior (IES), dentre outras características, por ofertarem não somente educação superior, como também educação básica, profissional e tecnológica.

Tal como as IES, são pluricurriculares e multicampi e contam com modelos administrativos heterogêneos; porém, com autonomia administrativa. Os IFs também possuem, dentre as suas diversas ações diretivas, a exigência legal de elaboração do Plano de Desenvolvimento Institucional (PDI), o qual contempla o plano estratégico institucional (BRASIL, 2008). Apesar de ser um importante norteador de ações de longo prazo, o PDI ainda é identificado como de baixa eficácia, predominando a carência de instrumentos e de sistemas de gestão que permitam o alcance dos objetivos estratégicos dessas Instituições (SÁNCHES; CAVALHEIRO, 2013; MARTINS, 2015).

Estudos referentes à abordagem do BSC para os IFs são ainda emergentes e apontam que ele pode ser uma alternativa auxiliar aos processos estratégicos de gestão (OLIVEIRA, 2014; MARTINS, 2015; NEIS, 2017; TEIXEIRA, 2017), apesar da escassez de dados sobre os resultados de sua aplicação efetiva. A literatura sobre o tema revela ainda a predominância de uma concepção top down, ou seja, que prioriza o entendimento e as informações emergidas de lideranças para a construção dos modelos estratégicos.

Entretanto, conforme Franco (1996), em organizações públicas, a identificação e a análise de explicações dos diversos indivíduos envolvidos nos processos organizacionais propiciam um processo democrático e descentralizado de formulação estratégica. Neste sentido, pode-se considerar uma formulação interativa da GE, induzida parcialmente pela direção institucional, numa abordagem top-down e que também emerge parcialmente do 
aprendizado de níveis hierárquicos mais baixos, num entendimento bottom-up (KIM; STING; LOCH, 2014).

A partir do exposto, levantam-se algumas questões: i) Quais adaptações são necessárias para que seja possível elaborar, propor e gerenciar um modelo de GE por meio do BSC para uma unidade de IF? ii) É possível defini-lo contemplando-se outras partes envolvidas, além da visão de suas lideranças?

Assim, a presente pesquisa teve por objetivo propor um modelo de GE para uma unidade de um IF, por meio da utilização adaptada do BSC. Para tanto, oportunizou-se realizar, de forma colaborativa: i) o diagnóstico organizacional da unidade por meio da análise de seus pontos fortes e fracos, ameaças e oportunidades; ii) a elaboração do seu PE e; iii) o desenvolvimento de um BSC para a GE da unidade, ambos (ii e iii) com o subsídio do diagnóstico organizacional e da atuação de um GT multidisciplinar.

\section{REFERENCIAL TEÓRICO}

\subsection{Balanced Scorecard APLICADO A ORGANIZAÇÕES PÚBLICAS}

A utilização do BSC na administração pública ainda é considerada modesta em comparação ao setor privado (HOQUE, 2014). Dentre os fatores críticos limitantes para a sua implantação, destaca-se a necessidade de apoio da alta gestão e de legitimação do modelo entre os servidores (BERGUE, 2005; GALAS; FORTE, 2005; CUNHA; KRATZ, 2016). Além disso, a própria cultura e a estrutura organizacional encontrada em alguns órgãos, muitas vezes hierarquizada e inflexível, dificultam sua efetivação (GALAS; FORTE, 2005; MARTINS, 2015; PINTO; ANGIUS, 2015).

A literatura evidencia que, para a efetiva adequação do BSC aos propósitos de uma organização pública, são necessárias adaptações na concepção de suas perspectivas, adequando-as às suas singularidades (KAPLAN; NORTON, 1997; BERGUE, 2005; BOCCI, 2005; GHELMAN, 2006). O sucesso financeiro não é considerado o principal objetivo organizacional, tampouco demonstra o cumprimento da missão organizacional (NIVEN, 2003; BOCCI, 2005), o qual é alcançado, essencialmente, pela satisfação dos clientes (NIVEN, 2003), ou seja, da sociedade. A perspectiva dos clientes passa, nesse caso, a ser o foco das outras perspectivas (KAPLAN; NORTON, 1997) e ocupa o topo da hierarquia no BSC (NIVEN, 2003; GHELMAN, 2006).

Ghelman (2006) destaca que, em organizações públicas, o bom andamento da 
perspectiva financeira impacta positivamente a perspectiva do crescimento e aprendizado organizacional. Essas duas perspectivas, por sua vez, conduzem a melhorias nos processos internos. As perspectivas crescimento e aprendizado organizacional e processos internos têm relação direta com a perspectiva clientes, já que uma organização com servidores capacitados e motivados tende a levar à melhoria permanente de sua gestão, a processos eficientes e a clientes satisfeitos.

Esse autor propõe o desdobramento da perspectiva de crescimento e aprendizado em outras duas: pessoas e modernização da administração, além da perspectiva financeira e orçamentária, em substituição à financeira. Busca-se um modelo de BSC para a gestão pública moderna, focada em resultados e orientada para o cidadão (GHELMAN, 2006).

\subsection{Balanced Scorecard em Institutos Federais}

Para IFs, a GE e a sua operacionalização por meio do BSC podem ser importantes auxílios, sobretudo frente à sua incipiente formação. São 38 IFs presentes em todos os Estados brasileiros, com mais de 640 campi em funcionamento, sendo que, entre 2003 e 2016, o MEC concretizou a construção de 500 novas unidades (MEC, 2016). Apesar de haver diversos exemplos de implementação de sucesso do BSC na área do ensino superior (NEIS, 2017), há características específicas que devem ser consideradas na definição dos seus planos e práticas estratégicas, diferenciando-se, portanto, de IES.

Com isso, visando-se a uma melhor compreensão do contexto estratégico de IFs, sintetizaram-se os estudos referentes à GE e ao uso do BSC encontrados na literatura (artigos, dissertações e teses disponíveis em bases de dados de livre acesso), conforme Quadro 1.

\begin{tabular}{|c|c|c|c|c|}
\hline Autor(es) & $\begin{array}{l}\text { Instituição } \\
\text { Pesquisada }\end{array}$ & Objetivo & Conclusões & $\begin{array}{c}\text { Perspectivas } \\
\text { adotadas }\end{array}$ \\
\hline $\begin{array}{c}\text { Ribeiro } \\
(2010)\end{array}$ & $\begin{array}{l}\text { IF do Rio } \\
\text { Grande do } \\
\text { Norte }\end{array}$ & $\begin{array}{l}\text { Analisar o enquadramento } \\
\text { do PDI às perspectivas do } \\
\text { BSC e o processo de } \\
\text { tomada de decisão com } \\
\text { base nos indicadores de } \\
\text { desempenho da } \\
\text { perspectiva financeira. }\end{array}$ & $\begin{array}{l}\text { Ainda que tenha sido possível o } \\
\text { enquadramento das ações } \\
\text { dispostas no PDI às perspectivas } \\
\text { do BSC, evidencia-se que os } \\
\text { indicadores não se vinculam } \\
\text { diretamente às ações do PDI, } \\
\text { sendo, portanto, incapazes de } \\
\text { medir o desempenho esperado. }\end{array}$ & $\begin{array}{c}\text { - Financeira } \\
\text { - Clientes } \\
\text { - Proc. Internos } \\
\text { - Aprendizado e } \\
\text { crescimento }\end{array}$ \\
\hline $\begin{array}{l}\text { Santos et } \\
\text { al. }(2012)\end{array}$ & $\begin{array}{l}\text { IF do Rio } \\
\text { de Janeiro }\end{array}$ & $\begin{array}{c}\text { Apresentar a metodologia } \\
\text { utilizada na } \\
\text { implementação do PE. }\end{array}$ & $\begin{array}{l}\text { O modelo proposto deve ser } \\
\text { ajustado a cada organização e é } \\
\text { fundamental a existência de } \\
\text { uma estrutura "ad hoc" para } \\
\text { acompanhar as atividades } \\
\text { previstas no PE. }\end{array}$ & $\begin{array}{l}\text { - Missão } \\
\text { - Operações } \\
\text { - Governança } \\
\text { - Recursos }\end{array}$ \\
\hline Heinzein & IF de Santa & Desenvolver uma proposta & Há necessidade de & - Cliente \\
\hline
\end{tabular}




\begin{tabular}{|c|c|c|c|c|}
\hline $\begin{array}{l}\text { e Streich } \\
(2013)\end{array}$ & $\begin{array}{l}\text { Catarina - } \\
\text { Campus } \\
\text { Jaraguá do } \\
\text { Sul }\end{array}$ & $\begin{array}{c}\text { do BSC para a gestão } \\
\text { estratégica dessa unidade. }\end{array}$ & $\begin{array}{l}\text { fortalecimento da cultura } \\
\text { estratégica da instituição para a } \\
\text { efetiva implementação do BSC. }\end{array}$ & $\begin{array}{c}\text {-Resp. Social } \\
\text { - Proc. internos } \\
\text { - Aprendizado e } \\
\text { crescimento }\end{array}$ \\
\hline $\begin{array}{l}\text { Araújo } \\
(2014)\end{array}$ & IF de Goiás & $\begin{array}{l}\text { Propor um modelo de BSC } \\
\text { para a GE orçamentária e } \\
\text { financeira da instituição. }\end{array}$ & $\begin{array}{l}\text { O BSC é de grande valia à } \\
\text { gestão orçamentária, desde que } \\
\text { sua efetiva implementação } \\
\text { supere alguns desafios. }\end{array}$ & $\begin{array}{l}\text { - Financeira } \\
\text { - Clientes } \\
\text { - Proc. Internos } \\
\text { - Aprendizado e } \\
\text { crescimento }\end{array}$ \\
\hline $\begin{array}{l}\text { Canuto } \\
(2014)\end{array}$ & IF do Ceará & $\begin{array}{c}\text { Investigar de que modo o } \\
\text { modelo de GE adotado se } \\
\text { alinha às perspectivas do } \\
\text { BSC. }\end{array}$ & $\begin{array}{l}\text { Verificou-se que o modelo de } \\
\text { GE está parcialmente alinhado } \\
\text { ao BSC, com uma priorização } \\
\text { da perspectiva clientes (alunos). } \\
\text { Evidencia-se a necessidade de } \\
\text { melhor balanceamento da GE. }\end{array}$ & $\begin{array}{l}\text { - Financeira } \\
\text { - Clientes } \\
\text { - Proc. Internos } \\
\text { - Aprendizado e } \\
\text { crescimento }\end{array}$ \\
\hline $\begin{array}{l}\text { Oliveira } \\
(2014)\end{array}$ & IF da Bahia & $\begin{array}{l}\text { Verificar se o BSC permite } \\
\text { o alinhamento das } \\
\text { diferentes diretivas } \\
\text { estratégicas adotadas na } \\
\text { instituição, visando à } \\
\text { definição de uma estratégia } \\
\text { única. }\end{array}$ & $\begin{array}{l}\text { Apesar de algumas lacunas } \\
\text { existentes no planejamento e } \\
\text { nos seus objetivos, o BSC } \\
\text { permite o alinhamento das } \\
\text { principais diretivas existentes, } \\
\text { tais como o PDI. }\end{array}$ & $\begin{array}{l}\text { - Sociedade } \\
\text { - Estudante } \\
\text { - Proc. internos } \\
\text { - Aprendizado e } \\
\text { crescimento } \\
\text { - Financeira }\end{array}$ \\
\hline $\begin{array}{l}\text { Santana } \\
(2014)\end{array}$ & $\begin{array}{l}\text { IF da Bahia } \\
\text { - Campus } \\
\text { Valença }\end{array}$ & $\begin{array}{l}\text { Apresentar um modelo de } \\
\text { aplicação do BSC. }\end{array}$ & $\begin{array}{l}\text { A adoção do modelo proposto } \\
\text { traria um retorno benéfico à } \\
\text { instituição, corroborando a } \\
\text { necessidade de um PE a médio e } \\
\text { longo prazo e uma reengenharia } \\
\text { de processos. }\end{array}$ & $\begin{array}{l}\text { - Financeira } \\
\text { - Clientes } \\
\text { - Proc. Internos } \\
\text { - Aprendizado e } \\
\text { crescimento }\end{array}$ \\
\hline $\begin{array}{l}\text { Martins } \\
\text { (2015) }\end{array}$ & $\begin{array}{l}\text { Instituto } \\
\text { Federal } \\
\text { Goiano }\end{array}$ & $\begin{array}{l}\text { Analisar a adequação da } \\
\text { utilização do BSC no } \\
\text { monitoramento do PDI. }\end{array}$ & $\begin{array}{c}\text { Verificou-se que a elaboração } \\
\text { do PDI a partir das perspectivas } \\
\text { do BSC agregou clareza, } \\
\text { objetividade e maior poder de } \\
\text { comunicação à estratégia } \\
\text { organizacional. }\end{array}$ & $\begin{array}{l}\text { - Missão } \\
\text { - Visão de } \\
\text { futuro } \\
\text { - Sociedade } \\
\text { - Proc. Internos } \\
\text { - Pessoas e } \\
\text { infraestrutura } \\
\text { - Orçamento }\end{array}$ \\
\hline $\begin{array}{c}\text { Menezes } \\
(2017)\end{array}$ & $\begin{array}{l}\text { IF da } \\
\text { Paraíba - } \\
\text { Campus } \\
\text { Picuí }\end{array}$ & $\begin{array}{l}\text { Propor um modelo de PE } \\
\text { para a instituição através } \\
\text { da utilização do BSC. }\end{array}$ & $\begin{array}{c}\text { O modelo construído é } \\
\text { adequado à realidade da } \\
\text { instituição e espera-se que sirva } \\
\text { como ferramenta de auxílio à } \\
\text { tomada de decisão. Entretanto, } \\
\text { sua implementação depende da } \\
\text { prévia apresentação à } \\
\text { comunidade acadêmica, visando } \\
\text { a sua legitimação. }\end{array}$ & $\begin{array}{l}\text { - Financeira e } \\
\text { orçamentária } \\
\text { - Pessoas } \\
\text { - Modernização } \\
\text { administrativa } \\
\text { - Proc. internos } \\
\text { - Clientes } \\
\text {-Sociedade/ } \\
\text { Cidadão }\end{array}$ \\
\hline $\begin{array}{l}\text { Teixeira } \\
(2017)\end{array}$ & $\begin{array}{l}\text { IF do } \\
\text { Triângulo } \\
\text { Mineiro }\end{array}$ & $\begin{array}{l}\text { Avaliar a implementação, } \\
\text { eficácia e efetividade dos } \\
\text { processos de PE e controle } \\
\text { orçamentário no período } \\
\text { de } 2014 \text { a } 2016 .\end{array}$ & $\begin{array}{c}\text { Concluiu-se que a } \\
\text { implementação do PE e controle } \\
\text { orçamentário iniciou uma } \\
\text { mudança na cultura } \\
\text { organizacional da instituição, } \\
\text { inclusive proporcionando uma } \\
\text { nova visão de gestão com a } \\
\text { inserção do BSC. }\end{array}$ & $\begin{array}{l}\text { - Sociedade } \\
\text { - Alunos } \\
\text { - Pessoas, } \\
\text { infraestrutura e } \\
\text { inovação } \\
\text { - Proc. internos } \\
\text { - Orçamentária } \\
\text { e financeira }\end{array}$ \\
\hline $\begin{array}{l}\text { Neis } \\
(2017)\end{array}$ & $\begin{array}{l}\text { IF Sul-rio- } \\
\text { grandense - } \\
\text { Campus } \\
\text { Venâncio } \\
\text { Aires }\end{array}$ & $\begin{array}{c}\text { Propor o uso do BSC } \\
\text { como ferramenta de } \\
\text { subsídio às decisões e ao } \\
\text { PE. }\end{array}$ & $\begin{array}{l}\text { Conclui-se que a utilização do } \\
\text { BSC pela equipe de gestão do } \\
\text { campus poderá auxiliar na } \\
\text { identificação e na clareza } \\
\text { quanto à missão e às estratégias } \\
\text { organizacionais. }\end{array}$ & $\begin{array}{l}\text { - Financeira } \\
\text { - Clientes } \\
\text { - Proc. Internos } \\
\text { - Aprendizado e } \\
\text { crescimento }\end{array}$ \\
\hline
\end{tabular}

Quadro 1 - Pesquisas científicas de GE e BSC para IFs

Fonte: Elaborado pelos autores (2018). 
Os estudos empíricos sobre GE em IFs são ainda reduzidos. Revelam-se informações limitadas quanto aos fatores que sustentam ou motivam a proposição de modelos de GE. Somente Santos et al. (2012), Santana (2014), Teixeira (2017) e Menezes (2017) citam a SWOT no processo de análise das variáveis ambientais para embasamento dos modelos desenvolvidos. Enquanto Canuto (2010), Ribeiro (2010), Araújo (2014), Santana (2014) e Neis (2017) conservam as perspectivas clássicas do BSC, os demais trabalhos sugerem adaptações nas perspectivas e na estrutura do BSC, para adequação às especificidades institucionais.

Em geral, as perspectivas adaptadas revelam preocupação com a finalidade institucional, com os clientes diretos (sociedade) e com os seus recursos. No entanto, somente os estudos de Heinzein e Streich (2013), Martins (2015) e Menezes (2017) estruturam suas perspectivas baseando-as ou justificando-as a partir da literatura científica. Heinzein e Streich (2013) e Martins (2015) estabelecem seus modelos tendo como ponto de partida principal estudos para IES; já Menezes (2017) propõe um modelo partindo-se de Ghelman (2006).

Enquanto Heinzein e Streich (2013) não levam em consideração a perspectiva financeira, Menezes (2017) e Teixeira (2017) apresentam a perspectiva orçamentária e financeira, evidenciando a dinâmica organizacional dos IFs: executam-se créditos orçamentários estabelecidos em lei e utilizam-se recursos financeiros visando-se atender às ações legais definidas. Heinzein e Streich (2013) e Martins (2015) consideram a perspectiva responsabilidade social e sociedade, em complemento e em substituição à perspectiva tradicional clientes, respectivamente.

Neis (2017) aponta para a necessidade de se aprimorar metodologias de medição e de gestão de desempenho institucional, sobretudo pelo risco de manutenção de IFs devido à redução gradativa do montante de recursos desde o ano de 2014, e aponta o BSC como alternativa. No entanto, são poucos os modelos efetivamente implantados, como os de Santos et al. (2012), Martins (2015) e Teixeira (2017).

Como principais barreiras para a execução de modelos de BSC para IFs, evidenciamse: resistência interna (ARAÚJO, 2014; SANTANA, 2014); necessidade de aprovação pela alta gestão (ARAÚJO, 2014); falta de legitimação junto à comunidade (MENEZES, 2017); ausência de cultura estratégica (HEINZEIN; STREICH, 2013); importância de haver pessoal capacitado e/ou treinamentos para a aplicação e acompanhamento do BSC (SANTOS et al., 2012; ARAÚJO, 2014; TEIXEIRA 2017).

Quanto à inserção da comunidade acadêmica no processo de estruturação do PE, embora se contemple a sua participação, ela ocorre essencialmente por meio de entrevistas 
e/ou questionários direcionados a ocupantes de cargos de gestão, com exceção aos trabalhos de Teixeira (2017), em que há relato de envolvimento da comunidade na elaboração do PDI e, Menezes (2017), que envolve docentes, discentes, técnicos administrativos e gestores na etapa de validação de dados, posteriormente ao diagnóstico organizacional.

Ponderando-se ainda os desafios referentes à precisão do alinhamento de estratégias únicas institucionais às estruturas multicampi e heterogêneas dos IFs de forma ampla, como por ora preconizado por meio do PDI, Heinzein e Streich (2013), Santana (2014), Menezes (2017) e Neis (2017) indicam a construção do PE e/ou propostas de seu desdobramento em modelos de BSC a partir das especificidades de unidades de IFs, em uma abordagem micro, assim como empregada no presente estudo.

\section{MATERIAL E MÉTODOS}

Esta pesquisa classifica-se como de finalidade aplicada e exploratória quanto ao seu objetivo, uma vez que busca explicitar o processo de PE da unidade estudada. Emprega-se a abordagem qualitativa para a condução do método de estudo de caso.

\subsection{Unidade de análise do estudo de caso}

O estudo foi realizado no Instituto Federal de Educação, Ciência e Tecnologia do Sul de Minas Gerais (IFSULDEMINAS), Campus Poços de Caldas. A unidade conta com sete anos de atividades e com a atuação de aproximadamente 170 servidores públicos efetivos, além de colaboradores eventuais. Sua estrutura organizacional é funcional, composta por uma Diretoria Geral (DG), responsável pela gestão geral da unidade e por duas diretorias sistêmicas (Diretoria de Administração e Planejamento (DAP) e Diretoria de Ensino, Pesquisa e Extensão (DEPE)), responsáveis pela gestão das áreas administrativas e de ensino, pesquisa e extensão, respectivamente.

Durante o período de realização da pesquisa, que se deu entre 2015 e 2017, tinha-se como panorama a ampliação de vagas para os cursos ofertados, atrelada ao crescimento infraestrutural do Campus. As ações de gestão envolviam o planejamento, a organização, a avaliação e o controle das atividades desenvolvidas por meio da definição de objetivos e de metas anuais, formalizadas por um Plano de Trabalho Anual (PTA).

Dentre as limitações do modelo gerencial adotado, salientam-se a falta de uma visão de longo prazo e a falta de definição de indicadores de desempenho. Adicionalmente, a 
adoção de uma estrutura organizacional hierarquizada, que dificulta a comunicação e a adoção de processos participativos de tomada de decisão, motivou a possibilidade de construção de um modelo de GE interativo para o norteamento de ações de médio a longo prazo no âmbito administrativo, do ensino, da pesquisa, da extensão, da inserção local e regional.

\subsection{Coleta de dados}

A coleta e a análise dos dados empíricos foram realizadas por intermédio de um GT multidisciplinar composto por docentes, por gestores representantes das diretorias sistêmicas (DAP e DEPE) e por técnicos administrativos, além de alunos bolsistas e dos pesquisadores autores deste artigo.

A técnica utilizada para a coleta de dados foi o grupo focal, que teve como propósito a obtenção de insights por meio da ausculta de um grupo de pessoas selecionadas a respeito de questões de interesse do pesquisador (MALHOTRA, 2001). Tem-se como premissa o fato de as pessoas tenderem a elaborar opiniões mediante processos de interação social, perspectiva que, por sua vez, mantém forte contraste com métodos em que grupos são interpretados com base em dados colhidos individualmente (CASTROL, 2013).

Krueger e Casey (2015) ponderam a importância de haver homogeneidade entre os grupos entrevistados, a fim de possibilitar um clima interativo à exposição de opiniões. Os autores apontam ainda que, para organizações públicas que buscam ser inclusivas em seu planejamento e no estabelecimento de suas metas, a técnica pode prover dados sobre como grupos de usuários dos serviços e servidores veem a organização e para onde ela deve ir.

A etapa de coleta de dados durou aproximadamente seis meses e ocorreu no ano de 2016. A composição dos grupos focais variou de três a oito integrantes, separando-se grupos de servidores e grupos de gestores (servidores ocupantes de cargos de gestão), para não se reprimir a exposição de opiniões, mantendo-se grupos homogêneos, conforme Krueger e Casey (2015). O entrevistador principal, pesquisador condutor das entrevistas e coautor deste artigo, possuía experiência na aplicação da técnica.

Formaram-se 24 grupos focais estruturados da seguinte forma: seis grupos formados por técnicos administrativos atuantes nos setores das três diretorias da instituição (DG, DAP e DEPE); seis grupos de gestores dos setores e das diretorias, compostos por docentes e por técnicos administrativos; nove grupos de docentes, servidores das coordenações de cursos; três grupos compostos por alunos representantes de turmas, divididos conforme a modalidade de curso ofertada (técnico integrado, técnico subsequente e superior). 
Essa divisão permitiu que todos os setores e coordenações de cursos da unidade participassem da fase de coleta de dados, construindo-se um diagnóstico organizacional compartilhado e democrático (FRANCO, 1996).

Foram realizadas reuniões prévias com cada grupo para se explicar os objetivos do trabalho e para apresentar a estrutura de tópicos que seria utilizada na condução dos grupos focais, a qual contava com questões abertas, para o levantamento dos principais pontos positivos e/ou negativos da instituição, bem como das principais ameaças e/ou oportunidades externas.

Em fase posterior, o entrevistador principal conduziu discussões sobre os tópicos com os grupos, separadamente. Alguns grupos apresentaram respostas escritas aos tópicos previamente apresentados. Representantes do GT participaram das discussões visando-se à validação dos dados. As entrevistas foram gravadas, transcritas e utilizadas na composição do banco de dados da pesquisa.

Foram obtidas 325 respostas referentes aos ambientes interno e externo em que a unidade se encontra inserida; sendo 78 referentes às forças institucionais, 114 quanto aos seus pontos fracos, 78 sobre oportunidades e 55 referentes às ameaças. As respostas foram categorizadas, ordenadas e resumidas, conforme relação disposta no Quadro 2 (seção 4.1).

\section{RESULTADOS E DISCUSSÃO}

A construção do modelo de GE e as principais discussões pertinentes dividem-se como segue: a seção 4.1 apresenta os resultados da análise SWOT, técnica de análise ambiental habitualmente utilizada no PE para o diagnóstico organizacional. Já a seção 4.2 apresenta a concepção do PE e do seu sistema de operacionalização (BSC) e explora: a adaptação das perspectivas do BSC; a definição de estratégias e objetivos alinhados aos propósitos organizacionais (missão, visão e valores) e direcionados às perspectivas do BSC; a estruturação do mapa estratégico e do plano de ações. A Figura 1 sintetiza os componentes do modelo proposto. 


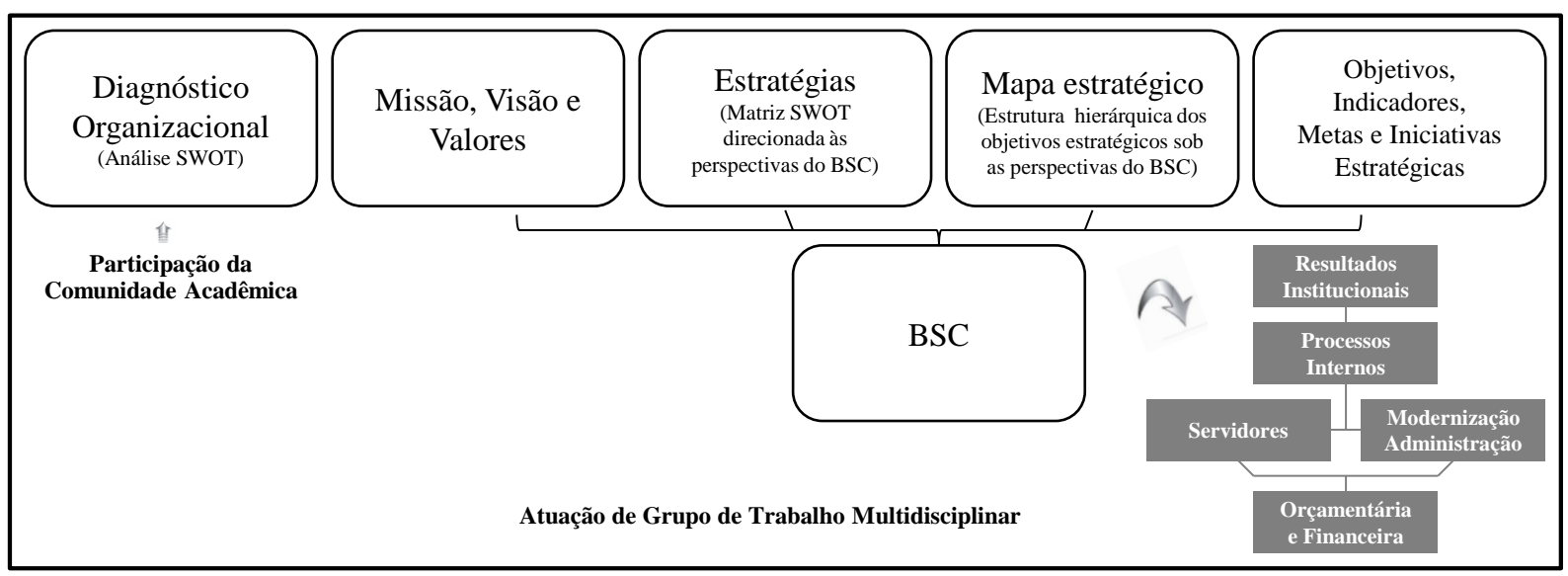

Figura 1 - GE para o IFSULDEMINAS, Campus Poços de Caldas

Fonte: Elaborada pelos autores (2018).

Para a elaboração do modelo, seguiram-se etapas de implementação do BSC propostas por Kaplan e Norton (2000). Destaca-se ainda que a participação da comunidade acadêmica no diagnóstico organizacional e a atuação de GT multidisciplinar visaram à legitimação do modelo proposto, conforme lacunas identificadas em Bergue (2005), Galas e Forte (2005), Cunha e Kratz (2016) e Menezes (2017), e à mitigação de resistência interna (ARAÚJO, 2014; SANTANA, 2014).

\subsection{Diagnóstico organizacional}

O envolvimento de toda a comunidade acadêmica foi primordial para a identificação das variáveis ambientais, sendo possível verificar a complementação de respostas: na maior parte dos casos, servidores ocupantes de cargos de gestão trouxeram respostas com enfoque na sua visão geral sobre a unidade, enquanto os demais servidores e estudantes ilustraram questões vinculadas ao seu setor/curso.

Evidencia-se, assim, a importância de se considerar diferentes abordagens (top-down, bottom-up) como subsídio ao processo de construção da estratégia organizacional (KIM; STING; LOCH, 2014), a partir das explicações dos diversos atores envolvidos (FRANCO, 1996). Nessa perspectiva, essa abordagem de abrangência sistêmica na etapa de diagnóstico pode ser considerada mais completa quando comparada a estudo similar de estruturação de PE para uma unidade de IF (MENEZES, 2017), em que prevalece a participação de técnicos administrativos e de docentes ocupantes de cargos de gestão.

Visando facilitar o posterior cruzamento das informações obtidas nessa etapa, para a criação das ações estratégicas, foram criadas categorias ordenadas e resumidas, representando a totalidade de informações obtidas. A coluna "\%" indica a contribuição relativa de cada 
categoria em termos percentuais por ponto-chave, podendo-se identificar as questões mais recorrentes para cada ponto-chave da análise SWOT, conforme mostrado no Quadro 2.

\begin{tabular}{|c|c|c|c|c|c|}
\hline \multicolumn{6}{|c|}{ Análise do ambiente interno } \\
\hline Pontos Fortes (Strengths) & Sigla & $\%$ & Pontos Fracos (Weaknesses) & Sigla & $\%$ \\
\hline $\begin{array}{l}\text { Esforços positivos para a execução do } \\
\text { trabalho }\end{array}$ & $\mathrm{S} 1$ & 58 & $\begin{array}{l}\text { Processos internos falhos } \\
\text { (comunicação falha, burocracia } \\
\text { excessiva, dentre outros) }\end{array}$ & W1 & 53 \\
\hline $\begin{array}{c}\text { Estrutura adequada com as obras em } \\
\text { andamento }\end{array}$ & S2 & 17 & Atuais problemas estruturais & W2 & 18 \\
\hline Qualificação dos servidores & S3 & 13 & $\begin{array}{c}\text { Escassez de recursos orçamentários e } \\
\text { financeiros }\end{array}$ & W3 & 9 \\
\hline Bons projetos pedagógicos & S4 & 6 & $\begin{array}{l}\text { Inadequada dinâmica de trabalho para } \\
\text { propiciar pesquisa, extensão e inovação }\end{array}$ & W4 & 6 \\
\hline Funcionalidade do organograma & S5 & 3 & Evasão escolar & W5 & 5 \\
\hline Suporte administrativo da Reitoria & S6 & 3 & Acervo bibliográfico deficitário & W6 & 4 \\
\hline $\begin{array}{l}\text { Respaldo em normas e legislações para a } \\
\text { execução dos processos de trabalho }\end{array}$ & S7 & 1 & $\begin{array}{l}\text { Inadequação da força de trabalho } \\
\text { (quadro de servidores insuficiente e } \\
\text { prestação de serviços terceirizados } \\
\text { muitas vezes desqualificada) }\end{array}$ & W7 & 3 \\
\hline & & & $\begin{array}{l}\text { Processo de verificação de demandas } \\
\text { por cursos não efetivo }\end{array}$ & W8 & 2 \\
\hline \multicolumn{6}{|c|}{ Análise do ambiente externo } \\
\hline Oportunidades (Opportunities) & Sigla & $\%$ & Ameaças (Threats) & Sigla & $\%$ \\
\hline Parcerias com entidades externas & $\mathrm{O} 1$ & 63 & $\begin{array}{l}\text { Problemas referentes ao orçamento e } \\
\text { recursos do governo }\end{array}$ & $\mathrm{T} 1$ & 16 \\
\hline $\begin{array}{c}\text { Oportunidades profissionais aos } \\
\text { estudantes na região do sul de Minas } \\
\text { Gerais }\end{array}$ & $\mathrm{O} 2$ & 12 & $\begin{array}{c}\text { Desconhecimento e falta de } \\
\text { visibilidade da instituição na cidade e } \\
\text { região }\end{array}$ & $\mathrm{T} 2$ & 10 \\
\hline Intercâmbio entre campi e reitoria & $\mathrm{O} 3$ & 12 & Falta de aproximação com o mercado & T3 & 8 \\
\hline $\begin{array}{l}\text { Estrutura, diversificação econômica e } \\
\text { localização de Poços de Caldas }\end{array}$ & $\mathrm{O} 4$ & 9 & Situação política e econômica do país & $\mathrm{T} 4$ & 7 \\
\hline $\begin{array}{l}\text { Possibilidade de crescimento do } \\
\text { Campus de Poços de Caldas }\end{array}$ & O5 & 4 & Entraves legais e burocráticos & T5 & 6 \\
\hline \multirow[t]{2}{*}{ Oferta de Cursos EAD } & O6 & 1 & $\begin{array}{c}\text { Concorrência principalmente no } \\
\text { ensino superior }\end{array}$ & T6 & 4 \\
\hline & & & $\begin{array}{l}\text { Falta de autonomia do campus } \\
\text { (dificuldade de trabalho colaborativo } \\
\text { entre unidades da rede, e falta de } \\
\text { autonomia financeira) }\end{array}$ & $\mathrm{T} 7$ & 1 \\
\hline
\end{tabular}

Quadro 2 - Análise SWOT

Fonte: Elaborado pelos autores (2018).

Ao comparar os resultados do Quadro 2 com trabalhos para IFs que fazem uso dessa técnica, verificam-se semelhanças, tais como oportunidade de parcerias com outras entidades (SANTOS et al., 2012; MENEZES, 2017), infraestrutura como força (SANTOS et al., 2012; MENEZES, 2017) e ameaças relacionadas a recursos (SANTOS et al., 2012; MENEZES, 2017), figurando-se dentre os pontos mais recorrentes, o que evidencia desafios e características em comum.

Todavia, muito embora existam questões convergentes, pontua-se a importância de adoção de uma abordagem micro para o entendimento da realidade organizacional, assim 
como Heinzein e Streich (2013), Santana (2014), Menezes (2017) e Neis (2017). A partir do diagnóstico detalhado da unidade, indicaram-se peculiaridades que enfatizam a heterogeneidade administrativa característica dos IFs.

\subsection{Elaboração do Balanced Scorecard}

O diagnóstico organizacional subsidiou a elaboração do BSC para gerenciar o PE da instituição. As perspectivas diferem-se da estrutura tradicional dos autores Kaplan e Norton (1997), dadas as especificidades dos IFs. Consideraram-se adaptações das propostas de Niven (2003), Bocci (2005) e Ghelman (2006), estabelecendo-se algumas correspondências com os estudos de BSC para IFs de Martins (2015), Menezes (2017) e Teixeira (2017).

O modelo proposto foi moldado em função de cinco perspectivas de desempenho: perspectiva orçamentária e financeira; perspectiva servidores; perspectiva modernização da administração; perspectiva dos processos internos e perspectiva dos resultados institucionais, conforme demonstrado na Figura 2.

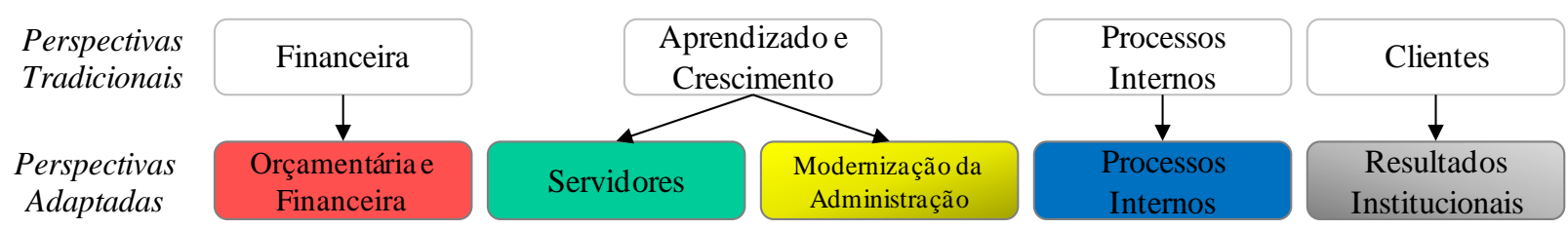

Figura 2 - Adpatação proposta para as perspectivas do BSC Fonte: Elaborada pelos autores (2018).

A perspectiva financeira foi renomeada para orçamentária e financeira para melhor representar a dinâmica organizacional, semelhantemente a Ghelman (2006) e tal como proposto por Menezes (2017) e Teixeira (2017) em estudos sobre a temática para IFs.

Ainda como Ghelman (2006), desdobrou-se a perspectiva aprendizado e crescimento em duas novas: servidores e modernização da administração. Busca-se destacar a importância dos servidores públicos e as suas inter-relações no trabalho e, paralelamente, a estrutura organizacional como provedora de meios para a geração de valor e de disseminação de conhecimento, desde que provida de renovações.

Martins (2015), Menezes (2017) e Teixeira (2017) revelam preocupações similares ao definirem pessoas e infraestrutura (MARTINS, 2015); pessoas, infraestrutura e inovação (TEIXEIRA, 2017); pessoas, modernização da administração (MENEZES, 2017), como perspectivas para modelos de BSC construídos para IFs. 
A quarta perspectiva, processos internos, foi a única a conservar a caracterização original do BSC, sendo também mencionada em quase todos os estudos de BSC para IFs (exceção é o estudo de Santos et al., (2012)), já que os processos internos podem ser considerados cernes do funcionamento organizacional.

A perspectiva processos internos do BSC modelado tem relação direta com os objetivos estratégicos traçados para a perspectiva resultados institucionais. Os elementos das perspectivas anteriores são os alicerces que subsidiam a satisfação plena dos clientes diretos: servidores, alunos, colaboradores, parceiros e outros usuários dos serviços e produtos ofertados e, da sociedade.

A perspectiva clientes foi redefinida para resultados institucionais, de modo a acentuar a ampla gama de aspectos propostos: busca-se atender às demandas dos clientes diretos e da sociedade, com ênfase ao desenvolvimento local e regional, dado o caráter de atuação da unidade (região sul mineira). Delineia-se, com essa perspectiva, o alcance da missão e da visão institucionais.

O foco no desenvolvimento regional é também revelado na perspectiva sociedade, do modelo de BSC para IF de Teixeira (2017), já que ela faz correspondência ao desenvolvimento das regiões em que a Instituição está inserida, relacionando-se, portanto, ao escopo estabelecido para a perspectiva resultados institucionais do BSC proposto.

Depois da definição das cinco perspectivas, foram elaboradas as estratégias organizacionais, cruzando-se pontos fortes $(\mathrm{S})$ e fracos $(\mathrm{W})$, oportunidades $(\mathrm{O})$ e ameaças $(\mathrm{T})$. Gerou-se, como resultado, uma matriz SWOT, em que ficaram evidenciadas estratégias para cada perspectiva, conforme proposto por Lee e Ko (2000).

O Quadro 3 apresenta uma amostra das estratégias levantadas para a perspectiva orçamentária e financeira. Ao se cruzar a ameaça T1 (problemas referentes ao orçamento e recursos do governo) com a oportunidade $\mathrm{O} 1$ (parcerias com entidades externas), gerou-se, por exemplo, a estratégia criar projetos de parcerias com fomento contínuo.

\begin{tabular}{|c|c|c|c|}
\hline \multicolumn{4}{|c|}{ Perspectiva Orçamentária e Financeira } \\
\hline T1 / O1 & S3 / T1 & O1 O4 / W3 W4 & O6 O4 O2 O1 / W3 \\
\hline $\begin{array}{c}\text { Criar projetos de } \\
\text { parcerias com fomento } \\
\text { contínuo. }\end{array}$ & $\begin{array}{c}\text { Gerar receitas por meio } \\
\text { de serviços/ } \\
\text { produtos. }\end{array}$ & $\begin{array}{c}\text { Buscar fomento externo } \\
\text { através de parcerias } \\
\text { locais. }\end{array}$ & $\begin{array}{c}\text { Ofertar Cursos EAD } \\
\text { conforme necessidades } \\
\text { regionais. }\end{array}$ \\
\hline
\end{tabular}

Quadro 3 - Matriz SWOT

Fonte: Elaborado pelos autores (2018). 
As estratégias definidas serviram de referência para a elaboração dos objetivos estratégicos e dos demais elementos do BSC. Considerando-se que os objetivos estratégicos devem buscar atingir os propósitos presentes e futuros da organização, decidiu-se adaptar a missão institucional do IFSULDEMINAS especificada em seu PDI (vigência 2014-2018) e criar a visão e os valores para a unidade, já que não existiam tais referenciais institucionais.

Apesar da definição de propósitos organizacionais adaptados às características de uma unidade de IF não ter sido encontrada na literatura consultada (predomina a menção de propósitos organizacionais definidos em PDI, abordando-os de forma macro), julga-se ser uma etapa relevante para a garantia do alinhamento estratégico às singularidades da estrutura organizacional. A relação de causa e efeito entre os objetivos estratégicos e sua interligação com os propósitos organizacionais é destacada no mapa estratégico da Figura 3.

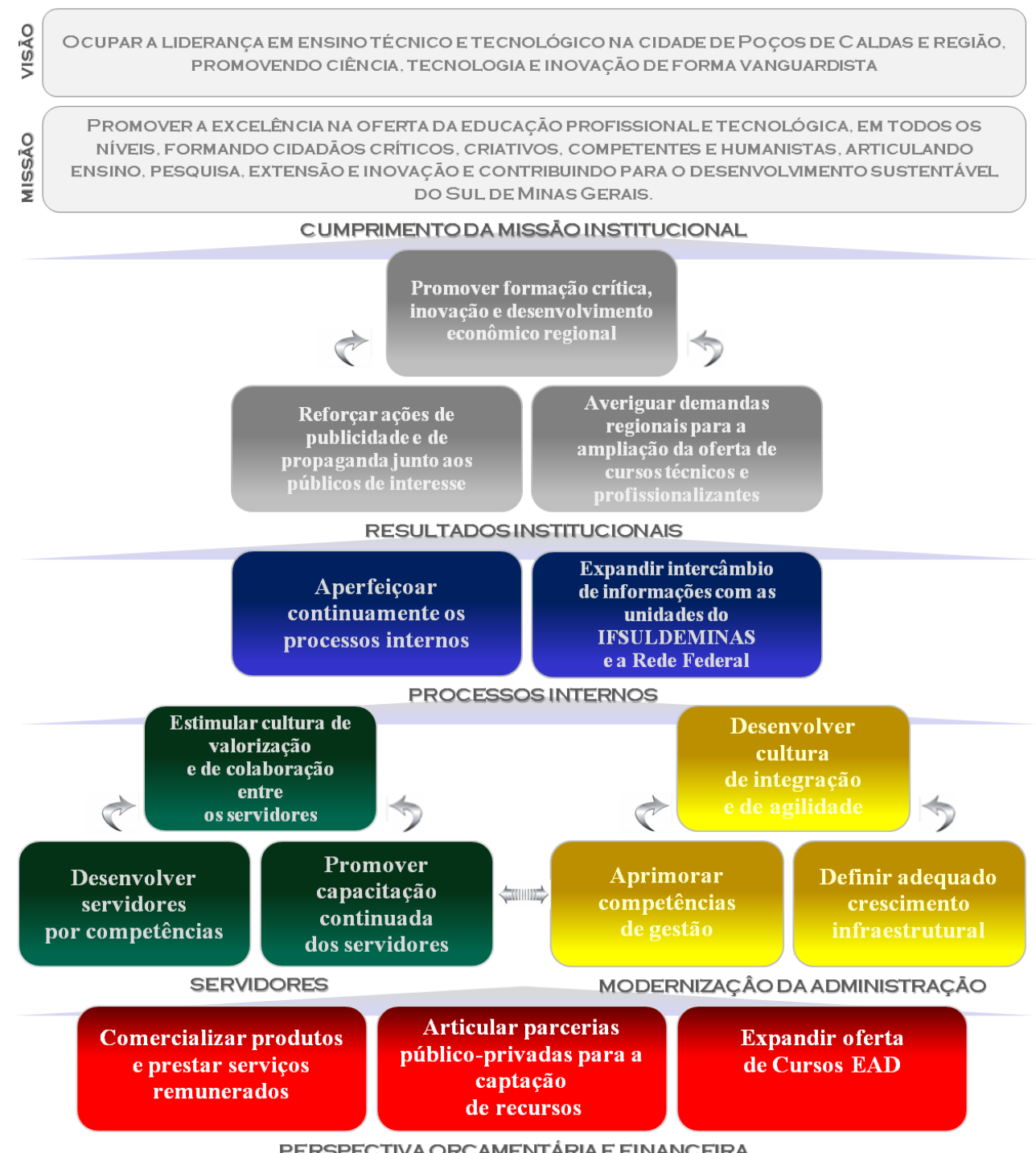

Figura 3 - Mapa Estratégico do IFSULDEMINAS, Campus Poços de Caldas Fonte: Elaborada pelos autores (2018). 
O mapa estratégico constituído ancora-se na necessidade de adequação do uso e da captação dos recursos por meio dos objetivos da perspectiva orçamentária e financeira, considerados a base do mapa estratégico por definirem fatores que podem garantir continuidade ou limitação das ações institucionais. A correta aplicação desses recursos correlaciona-se diretamente aos objetivos estratégicos das perspectivas servidores e modernização da administração e somente será possível caso ocorram a atualização administrativa e a estruturação das relações de trabalho. As ações dessas perspectivas impactam positivamente no aprimoramento contínuo dos processos internos.

Os objetivos da perspectiva resultados institucionais evidenciam ações que efetivam o cumprimento da missão institucional e de situações futuras almejadas, particularmente no tocante à formação crítica, à geração de inovação e ao desenvolvimento econômico regional.

Buscou-se alinhar os objetivos estratégicos com indicadores, metas e responsáveis pelo seu cumprimento (iniciativas estratégicas), de acordo com o Quadro 4. O modelo proposto baseia-se em um planejamento de longo prazo (cinco anos), com o estabelecimento de metas anuais para facilitar o processo de seu gerenciamento e controle.

\begin{tabular}{|c|c|c|c|}
\hline Objetivos Estratégicos & Indicadores & Metas & Iniciativas Estratégicas \\
\hline \multicolumn{4}{|c|}{$\begin{array}{c}\text { Perspectiva Resultados Institucionais } \\
\text { (Como atender às expectativas dos clientes internos e externos?) }\end{array}$} \\
\hline \multirow{2}{*}{$\begin{array}{c}\text { Reforçar ações de publicidade } \\
\text { e de propaganda junto aos } \\
\text { públicos de interesse. }\end{array}$} & $\begin{array}{c}\text { Campanhas publicitárias } \\
\text { efetivadas. }\end{array}$ & $\begin{array}{c}\text { Definir } 3 \text { grandes } \\
\text { campanhas publicitárias. }\end{array}$ & $\begin{array}{l}\text { Assessoria de } \\
\text { Comunicação. }\end{array}$ \\
\hline & $\begin{array}{l}\text { Parcerias institucionais } \\
\text { concretizadas. }\end{array}$ & $\begin{array}{l}\text { Visitar } 20 \text { empresas da } \\
\text { região vislumbrando } \\
\text { parcerias. }\end{array}$ & DAP, DEPE. \\
\hline \multirow{4}{*}{$\begin{array}{c}\text { Promover inovação e } \\
\text { desenvolvimento econômico } \\
\text { regional. }\end{array}$} & $\begin{array}{l}\text { Egressos inseridos no } \\
\text { mercado de trabalho. }\end{array}$ & $\begin{array}{l}\text { Mapear situação de } \\
\text { egressos. }\end{array}$ & Pesquisador Institucional. \\
\hline & $\begin{array}{c}\text { Formalização de Projetos } \\
\text { de Empresas Juniores } \\
\text { (EJs). }\end{array}$ & $\begin{array}{l}\text { Formalizar e executar } 3 \\
\text { projetos. }\end{array}$ & Coordenadores de Ej's. \\
\hline & Patentes registradas. & $\begin{array}{l}\text { Registrar pelo menos } \\
\text { uma patente. }\end{array}$ & $\begin{array}{l}\text { Escritório Local de } \\
\text { Transferência de } \\
\text { Tecnologia (ELITT). }\end{array}$ \\
\hline & Empresas incubadas. & Incubar duas empresas. & ELITT. \\
\hline $\begin{array}{l}\text { Ampliar a oferta de cursos e } \\
\text { serviços. }\end{array}$ & $\begin{array}{c}\text { Demanda para cursos e } \\
\text { outros serviços } \\
\text { prospectada. }\end{array}$ & $\begin{array}{c}\text { Estudar mercado para a } \\
\text { definição de abertura de } \\
\text { novos cursos e outros } \\
\text { serviços. }\end{array}$ & DG, DAP, DEPE. \\
\hline \multicolumn{4}{|c|}{$\begin{array}{c}\text { Perspectiva Processos Internos } \\
\text { (Como otimizar os processos de trabalho?) }\end{array}$} \\
\hline \multirow[t]{2}{*}{$\begin{array}{l}\text { Aperfeiçoar continuamente os } \\
\text { processos internos. }\end{array}$} & $\begin{array}{l}\text { Eficiência dos Processos } \\
\text { Internos. }\end{array}$ & $\begin{array}{l}\text { Levantar todos os } \\
\text { processos institucionais } \\
\text { realizados. }\end{array}$ & DG, DAP, DEPE. \\
\hline & & $\begin{array}{l}\text { Mapear, de forma macro, } \\
\text { todos os processos }\end{array}$ & DG, DAP, DEPE. \\
\hline
\end{tabular}




\begin{tabular}{|c|c|c|c|}
\hline & & institucionais. & \\
\hline & $\begin{array}{l}\text { Demandas de compras } \\
\text { planejadas. }\end{array}$ & $\begin{array}{l}\text { Definir demanda } \\
\text { institucional de compras } \\
\text { a curto, médio e longo } \\
\text { prazo. }\end{array}$ & $\begin{array}{l}\text { DG, DAP, DEPE e } \\
\text { Coordenadoria de } \\
\text { Planejamento. }\end{array}$ \\
\hline $\begin{array}{l}\text { Expandir intercâmbio de } \\
\text { informações com as unidades } \\
\text { do IFSULDEMINAS e da } \\
\text { Rede Federal. }\end{array}$ & $\begin{array}{l}\text { Processos revistos e } \\
\text { otimizados. }\end{array}$ & $\begin{array}{l}\text { Reduzir prazo de } \\
\text { execução de dois } \\
\text { processos em cada } \\
\text { diretoria sistêmica. }\end{array}$ & DAP, DEPE. \\
\hline \multicolumn{4}{|c|}{$\begin{array}{c}\text { Perspectiva Servidores } \\
\text { (Como definir e desenvolver as relações de trabalho?) }\end{array}$} \\
\hline \multirow[t]{3}{*}{$\begin{array}{l}\text { Estimular cultura de } \\
\text { valorização e de colaboração } \\
\text { entre os servidores. }\end{array}$} & $\begin{array}{l}\text { Encontros de } \\
\text { conscientização } \\
\text { promovidos. }\end{array}$ & $\begin{array}{l}\text { Promover } 1 \text { encontro a } \\
\text { cada semestre. }\end{array}$ & $\begin{array}{c}\text { DG, DAP, Coordenadoria } \\
\text { de Administração e } \\
\text { Finanças. }\end{array}$ \\
\hline & $\begin{array}{c}\text { Ações de saúde } \\
\text { ocupacional promovidas. }\end{array}$ & $\begin{array}{c}\text { Realizar } 1 \text { campanha por } \\
\text { bimestre com temática } \\
\text { relacionada. }\end{array}$ & $\begin{array}{c}\text { Coordenadoria de } \\
\text { Administração e Finanças. }\end{array}$ \\
\hline & $\begin{array}{c}\text { Servidores em } \\
\text { colegiados e comissões. }\end{array}$ & $\begin{array}{c}\text { Nomear } 15 \text { novos } \\
\text { servidores sem repetição } \\
\text { (formato de rodízio), } \\
\text { para a participação em } \\
\text { colegiados e comissões / } \\
\text { ano. }\end{array}$ & $\mathrm{DG}$ \\
\hline $\begin{array}{l}\text { Promover capacitação } \\
\text { continuada dos servidores. }\end{array}$ & $\begin{array}{l}\text { Servidores capacitados } \\
\text { anualmente. }\end{array}$ & $\begin{array}{l}\text { Formalizar e efetivar } \\
\text { plano anual de } \\
\text { capacitação dos } \\
\text { servidores. }\end{array}$ & $\begin{array}{c}\text { Coordenadoria de } \\
\text { Administração e Finanças. }\end{array}$ \\
\hline $\begin{array}{l}\text { Desenvolver servidores por } \\
\text { competências. }\end{array}$ & $\begin{array}{c}\text { Competências e } \\
\text { habilidades da força de } \\
\text { trabalho. }\end{array}$ & $\begin{array}{l}\text { Mapear competências } \\
\text { atuais e necessidades de } \\
\text { novos cargos. }\end{array}$ & DAP, Chefias. \\
\hline \multicolumn{4}{|c|}{$\begin{array}{l}\text { Perspectiva Modernização da Administração } \\
\text { (Como tornar as ações de gestão efetivas?) }\end{array}$} \\
\hline $\begin{array}{l}\text { Aprimorar competências da } \\
\text { gestão. }\end{array}$ & $\begin{array}{l}\text { Gestores capacitados } \\
\text { anualmente. }\end{array}$ & $\begin{array}{c}\text { Contratar curso de } \\
\text { capacitação de gestores } \\
\text { de no mínimo } 80 \text { horas / } \\
\text { ano. }\end{array}$ & $\begin{array}{c}\text { DAP, Coordenadoria de } \\
\text { Administração e Finanças. }\end{array}$ \\
\hline \multirow[t]{2}{*}{$\begin{array}{l}\text { Desenvolver cultura de } \\
\text { integração e de agilidade. }\end{array}$} & $\begin{array}{l}\text { Práticas de trabalho } \\
\text { aperfeiçoadas. }\end{array}$ & $\begin{array}{l}\text { Criar campanhas } \\
\text { bimestrais de boas } \\
\text { práticas de trabalho. }\end{array}$ & $\begin{array}{l}\text { Assessoria de } \\
\text { Comunicação. }\end{array}$ \\
\hline & $\begin{array}{l}\text { Satisfação com os } \\
\text { serviços. }\end{array}$ & $\begin{array}{l}\text { Promover pesquisa anual } \\
\text { de satisfação de serviços. }\end{array}$ & DAP, DEPE. \\
\hline $\begin{array}{l}\text { Definir adequado crescimento } \\
\text { da infraestrutura institucional. }\end{array}$ & Plano Diretor. & $\begin{array}{l}\text { Formalizar Plano } \\
\text { Diretor. }\end{array}$ & DG, DAP, DEPE. \\
\hline \multicolumn{4}{|c|}{$\begin{array}{c}\text { Perspectiva Orçamentária e Financeira } \\
\text { (Como incrementar os recursos orçamentários e financeiros para garantir a continuidade das atividades } \\
\text { institucionais?) }\end{array}$} \\
\hline \multirow[t]{3}{*}{$\begin{array}{l}\text { Articular parcerias público- } \\
\text { privadas para a captação de } \\
\text { recursos. }\end{array}$} & $\begin{array}{l}\text { Termos de Cooperação } \\
\text { (TC) formalizados com } \\
\text { contrapartida financeira. }\end{array}$ & $\begin{array}{l}\text { Efetivar pelo menos um } \\
\text { TC com contrapartida } \\
\text { financeira / ano. }\end{array}$ & DG, DAP, DEPE. \\
\hline & $\begin{array}{l}\text { Atualização de mailing } \\
\text { de parceiros. }\end{array}$ & $\begin{array}{c}\text { Somar } 5 \text { novas parcerias } \\
\text { anuais. }\end{array}$ & $\begin{array}{l}\text { Assessoria de } \\
\text { Comunicação. }\end{array}$ \\
\hline & $\begin{array}{l}\text { Cursos com isenção de } \\
\text { taxas provenientes de } \\
\text { parcerias. }\end{array}$ & $\begin{array}{l}\text { Articular } 2 \text { cursos } \\
\text { capacitantes / ano. }\end{array}$ & DAP, CAF. \\
\hline Comercializar produtos e & Produtos/serviços & Prospectar produtos e & DAP, DEPE. \\
\hline
\end{tabular}




\begin{tabular}{|l|c|c|c|}
\hline prestar serviços remunerados. & disponibilizados. & serviços e iniciar oferta. & \\
\cline { 2 - 4 } & Receitas Geradas. & $\begin{array}{c}\text { Gerar receitas } \\
\text { proporcionais a 10\% do } \\
\text { orçamento. }\end{array}$ & DAP, DEPE. \\
\hline $\begin{array}{l}\text { Expandir a oferta de cursos } \\
\text { EAD. }\end{array}$ & Cursos ofertados. & $\begin{array}{c}\text { Ofertar pelo menos 2 } \\
\text { cursos EAD. }\end{array}$ & $\begin{array}{c}\text { DEPE, Coordenadoria de } \\
\text { EAD. }\end{array}$ \\
\cline { 2 - 4 } & Alunos matriculados. & $\begin{array}{c}\text { Matricular quantitativo } \\
\text { de alunos EAD que } \\
\text { correspondam a 10\% dos } \\
\text { alunos presenciais. }\end{array}$ & $\begin{array}{c}\text { DEPE, Coordenadoria de } \\
\text { EAD. }\end{array}$ \\
\hline
\end{tabular}

Quadro 4 - Modelo do BSC para o IFSULDEMINAS, Campus Poços de Caldas

Fonte: Elaborado pelos autores (2018).

O acompanhamento e a avaliação contínua dos indicadores e das metas poderão garantir o alcance dos resultados estratégicos traçados. Frisa-se que, ao estabelecer responsáveis (iniciativas estratégicas) e metas com prazos para o alcance dos objetivos estratégicos definidos, a proposta sintetizada no Quadro 4 mostra detalhes não encontrados nos demais modelos de GE/BSC para IFs resumidos no Quadro 1.

\section{CONSIDERAÇÕES FINAIS}

A presente pesquisa contribui para a redução de lacunas sobre estudos empíricos de utilização do BSC em organizações públicas, particularmente para IFs. Consideraram-se como relevantes contribuições frente às omissões da literatura relacionada: uso de abordagem detalhada quanto ao diagnóstico das variáveis ambientais para a construção do modelo de GE; adoção de mecanismos participativos para a estruturação do modelo; apresentação de uma proposta completa e minuciosa de GE para IFs; estruturação de um BSC diferenciado.

Destaca-se que a realização de grupos focais envolvendo os diversos níveis institucionais na etapa de diagnóstico, bem como a atuação de um GT multidisciplinar para a elaboração do modelo, geraram um enfoque compartilhado (descentralizado), democrático e interativo e podem ser apontados como relevantes achados.

A nova arquitetura proposta para o BSC, adequada às singularidades da Instituição, especialmente em função de seu contexto local e regional de atuação, em conjunto com seus objetivos, indicadores, metas e iniciativas, podem ser considerados valiosas contribuições teóricas. A nova estrutura do BSC é passível de ser aplicada a instituições semelhantes para verificação de sua validade e possibilidade de generalização externa e/ou adaptações.

Dentre as implicações gerenciais, a expectativa é de que o modelo de GE proposto, uma vez aplicado, coopere potencialmente para a melhoria dos indicadores institucionais e para a ampliação de seu escopo de atuação de forma planejada e controlada. 
Quanto às limitações desta pesquisa, além daquelas relacionadas às restrições de um estudo de caso único, aponta-se a não identificação de fatores críticos de sucesso (FCS) para o BSC proposto, bem como o seu acompanhamento e gestão. Conforme Kaplan e Norton (2000), essas são consideradas etapas de implementação do BSC e não foi objeto de análise, uma vez que o modelo proposto ainda não se encontra implementado. E mesmo tendo sido construído de forma colaborativa e compartilhada, é importante que o modelo seja apresentado à comunidade acadêmica para deliberações finais.

Quanto à sincronização do modelo de GE criado com o PDI do IFSULDEMINAS, optou-se por alinhá-lo à missão institucional do IFSULDEMINAS, não o vinculando, diretamente, aos objetivos e metas do PDI institucional. Portanto, outras perspectivas para investigações futuras poderão explorar as inter-relações entre os modelos de GE construídos para unidades de IFs e o PDI; detalhar barreiras (FCS) à implantação do BSC em IFs; analisar os resultados efetivos do BSC em IFs; aplicar e/ou propor o aperfeiçoamento do modelo proposto.

\title{
BALANCED SCORECARD AS SUPPORT FOR THE STRATEGIC MANAGEMENT OF A UNIT OF A FEDERAL INSTITUTE OF TECHNOLOGICAL EDUCATION
}

\begin{abstract}
The research aims to propose a strategic management (SM) model for a unit of a Federal Institute of Education, Science and Technology (FI), formalizing it through the adaptation of the Balanced Scorecard (BSC). The case study was based on the collection of data by applying focus group technique and the information obtained was interpreted qualitatively by a multidisciplinary working group. Through the construction and participatory proposition of an alternative BSC in a public organization, it contributes to the reduction of gaps related to i) resistance and absence of insertion of the academic community in the SM process and ii) use of BSC in IFs. It was evidenced i) the more active participation of the community in the process of organizational diagnosis and structuring of the model, seeking its effective legitimation; ii) the definition of organizational strategies for the systematization of Strategic Planning and iii) the structuring of an SM model that is appropriate to the singularities of the institution, consolidated by the BSC. The new architecture of the BSC can be replicated to other similar educational institutions in order to provide comparative studies and verify it external validity. The study also reduces omissions from the SM literature in FIs, detailing the process of devising strategic practices for improving organizational performance.
\end{abstract}

Keywords: Strategic Management. Balanced Scorecard. Federal Institute of Education, Science and Technology. 


\section{REFERÊNCIAS}

ARAÚJO, Margarida Silva de. Desafios da implementação do Balanced Scorecard na gestão orçamentária: estudo de caso no Instituto Federal de Educação, Ciência e Tecnologia de Góias. 2014. 170 f. Dissertação (Mestrado Profissional em Administração) - Faculdade Alves Faria, Goiânia, 2014.

BERGUE, Sandro Trescastro. Gestão estratégica de pessoas e Balanced Scorecard em organizações públicas. Análise - Revista de Administração da PUCRS, Porto Alegre, v. 16, n. 2, p. 265-284, 2005.

BOCCI, Fabrizio. A new BSC architecture for the public sector. Perspectives on Performance, Itália, v. 4, n.3, p. 30-32, 2005.

BRASIL. Lei no 11.892, de 29 de dezembro de 2008. Institui a Rede Federal de Educação Profissional, Científica e Tecnológica, cria os Institutos Federais de Educação, Ciência e Tecnologia e dá outras providências. Brasília, DF, Diário Oficial da República Federativa do Brasil, seção 1, p. 3, 2008.

CANUTO, Francisco Ebison Souto. Gestão estratégica à luz das perspectivas do Balanced Scorecard: um estudo no Instituto Federal de Educação, Ciência e Tecnologia do Ceará. 2014. 150 f. Dissertação (Mestrado Profissional em Administração e Controladoria) Universidade Federal do Ceará, Fortaleza, 2014.

CASTRO, Alexandre de Carvalho. Produção offshore na Bacia de Campos (RJ): a perspectiva da Psicologia do Trabalho. Gestão \& Produção, São Carlos, v. 20, n. 4, p. 833-846, 2013.

CUNHA, Marcos Ribeiro; KRATZ, Lucia. Fatores críticos de sucesso no processo de implementação do Balanced Scorecard: um estudo de caso nas instituições federais de ensino superior. Revista de Ciências da Administração, Florianópolis, v. 18, n. 46, p. 96-108, 2016.

FRANCO, Huertas. O método PES - Entrevista com Matus. São Paulo: FUNDAP, 1996.

GALAS, Eduardo Santos; FORTE, Sérgio Henrique Arruda Cavalcante. Fatores que interferem na implantação de um modelo de Gestão Estratégica baseado no Balanced Scorecard: estudo de caso em uma instituição pública. Revista de Administração Mackenzie, São Paulo, v. 6, n. 2, p. 87-111, 2008.

GHELMAN, Sílvio. Adaptando o Balanced Scorecard aos preceitos da nova gestão pública. 2006. 86 f. Dissertação (Mestrado Profissional em Sistemas de Gestão de Qualidade Total) - Universidade Federal Fluminense, Niterói, 2006.

HEINZEIN, Daiane Aparecida de Melo; STREICH, Kenia Regina. Proposição do Balanced Scorecard para suporte à Gestão Estratégica de uma instituição de ensino público. Revista ADMpg Gestão Estratégica, Ponta Grossa, v. 6, n. 2, p. 77-85, 2013.

HOQUE, Zarihul. 20 years of studies on the Balanced Scorecard: trends, accomplishments, gaps and opportunities for future research. The British Accounting Review, Reino Unido, v. 46, n. 1, p. 33-59, 2014. 
KAPLAN, Robert S.; NORTON, David P. Balanced scorecard: a estratégia em ação. 21. ed. Rio de Janeiro: Campus, 1997.

KAPLAN, Robert S.; NORTON, David P. Organização orientada para a estratégia: como as empresas que adotam o Balanced Scorecard prosperam no ambiente de negócios. 12. ed. Rio de Janeiro: Campus, 2000.

KIM, Yoon Hee; STING, Fabian J.; LOCH, Christoph H. Top-down, bottom-up, or both? Toward an integrative perspective on operations strategy formation. Journal of Operations Management, Holanda, v. 32, n.1, p. 462-474, 2014.

KRUEGER, Richard A.; CASEY, Marry Anne. Focus groups. a practical guide for applied research. 5. ed. Thousand Oaks: Sage, 2015.

LEE, S. F.; KO, Andrew Sai On. Building Balanced Scorecard with SWOT analysis, and implementing "Sun Tzu's. The art of business management strategies" on QFD methodology. Managerial Auditing Journal, Reino Unido, v. 15, n. 1, p. 68-76, 2000.

MALHOTRA, Naresh K. Pesquisa de marketing: uma orientação aplicada. Porto Alegre: Bookman, 2001.

MARTINS, Felipe Longo. A construção do Plano de Desenvolvimento Institucional na perspectiva do pensamento estratégico: o caso do Instituto Federal Goiano. 2015. 103 p. Dissertação (Mestrado em Desenvolvimento Regional) - Faculdade Alves Faria, Goiânia, 2015.

MENEZES, Cláudio Lima de. Utilização do Balanced Scorecard como ferramenta de planejamento estratégico: uma proposta de implantação no Instituto Federal da Paraíba Campus Picuí. 2017. 97 p. Dissertação (Mestrado em Gestão Pública) - Universidade Federal do Rio Grande do Norte, Natal, 2017.

MINISTÉRIO DA EDUCAÇÃO. Portal da Rede Federal de Educação Profissional, Científica e Tecnológica. Histórico. 2016. Disponível em: http://redefederal.mec.gov.br/ historico. Acesso em: 22 jul.2018.

NEIS, Adelaide Marli. Aplicação do Balanced Scorecard no campus Venâncio Aires do Instituto Federal Sul-Rio-Grandense. 2017. 195 p. Dissertação (Mestrado em Administração das Organizações Educativas) - Escola de Educação do Politécnico do Porto, Porto, 2017.

NIVEN, Paul R. Balanced Scorecard step-by-step: maximizing performance and maintaining results. New York: J. Wiley, 2003.

OLIVEIRA, Ana Cláudia Sá. Aplicação do Balanced Scorecard à Gestão Estratégica do Instituto Federal de Educação, Ciência e Tecnologia da Bahia. 2014. 107 p. Dissertação (Mestrado em Administração) - Universidade Federal da Bahia, Salvador, 2014.

PINTO, Miriam Magdala; ANGIUS, Bruno Mannato. Balanced Scorecard na prática da gestão de um laboratório acadêmico. Revista Ibero Americana de Estratégia, São Paulo, v. 14, n. 1, p. 127-138, 2015.

RIBEIRO, Valdelúcio Pereira. Ações e indicadores de desempenho organizacional vistos 
sob a ótica do Balanced Scorecard: um estudo no Instituto Federal de Educação, Ciência e Tecnologia do Rio Grande do Norte. 2010. 118 f. Dissertação (Mestrado Profissional em Administração) - Universidade Potiguar, Natal, 2010.

RODRIGUES, Gustavo de Oliveira. Aplicação da gestão de processos em uma universidade pública do estado de São Paulo. 2015. 116 f. Dissertação (Mestrado em Engenharia de Produção) - Universidade Estadual Paulista Júlio de Mesquita Filho, Bauru, 2015.

SÁNCHEZ, Jesusa Rita Fidalgo; CAVALHEIRO, Andrei Zwetsch. O PDI como ferramenta de gestão: orientações para elaboração. In: Fórum de Desenvolvimento Institucional da Rede Federal de Educação Profissional e Tecnológica (FDI). 2013.

SANTANA, Ricardo Silva de. Aplicação de métodos de gestão a instituições de ensino: análise do Instituto Federal de Educação, Ciência e Tecnologia da Bahia - Campus Valença, sob a perspectiva do balance scorecard. 2014. 158 p. Dissertação (Mestrado Profissional em Administração) - Universidade Federal da Bahia, Salvador, 2014.

SANTOS, João Alberto Neves dos; SEPULVEDA, Fernando A. Miranda; SERRAVALE, Alberto França. Implementação do Planejamento Estratégico no Instituto Federal de Educação, Ciência e Tecnologia do Rio de Janeiro. In: Simpósio de Excelência em Gestão e Tecnologia (SeGeT), IX., 2012, Rio de Janeiro. Anais [...]. Rio de Janeiro: SEGet, 2012.

TEIXEIRA, Augusto César. Os processos de Planejamento Estratégico e controle orçamentário de uma instituição de educação superior, básica e profissional: o caso IFTM. 2017. 168 p. Dissertação (Mestrado em Gestão Organizacional) - Universidade Federal de Uberlândia, Uberlândia, 2017.

\section{DADOS DOS AUTORES}

\section{Marina Gomes Murta Moreno}

E-mail: marina.murta@ifsuldeminas.edu.br

Currículo Lattes: http://lattes.cnpq.br/9377432263248172

Graduação em engenharia de produção pela Universidade Federal de Viçosa (UFV, 2007). Mestre em ciência e engenharia de materiais pela Universidade Federal de Alfenas (UNIFAL, 2014). Doutoranda em Engenharia de Produção pela Universidade Federal de São Carlos (UFSCar. Área: Gestão de PD\&I. Previsão de doutoramento: 2021). Desde 2012, exerce o cargo de Técnica-Administrativa em Educação no Instituto Federal do Sul de Minas (IFSULDEMINAS, Campus Poços de Caldas).

\section{Cassio Henrique Garcia Costa}

E-mail: cassiohenrique.costa@cefetmg.br

Currículo Lattes: http://lattes.cnpq.br/9186021224383863

Professor do CEFET-MG, Campus Nepomuceno. Doutor em Administração pela Universidade Federal de Lavras (UFLA), área: Gestão de Negócios, Economia e Mercados. Mestre em Administração pela UFLA, área: Dinâmica e Gestão de Cadeia Produtivas. Bacharel em Administração pela UFLA. Foi professor temporário da UFLA. Atuou por 9 anos no Centro de Inteligência em Mercados (UFLA) na prestação de serviços e na coordenação de projetos de pesquisa e extensão. Atuou por 5 anos como professor no Instituto Federal do Sul de Minas (IFSULDEMINAS), Campus Poços de Caldas onde foi professor do 
mestrado PROFEPT, coordenador da empresa júnior multidisciplinar do campus e de projetos de extensão/inovação. Trabalha com os temas: Economia, Controladoria e Finanças, Gestão de Riscos, Estratégia Empresarial, Empreendedorismo e Inovação.

\section{Geraldo Tessarini Junior}

E-mail: geraldo.tessarini@gmail.com

Currículo Lattes: http://lattes.cnpq.br/5837053265871206

Mestrando em Engenharia de Produção pela Universidade Federal de São Carlos (UFSCar, Campus Sorocaba). Bacharel em Administração pelo Centro Universitário da Fundação de Ensino Octávio Bastos (UNIFEOB). Técnico-Administrativo em Educação do Instituto Federal de São Paulo (IFSP). 